\title{
Prone position in intubated, mechanically ventilated patients with COVID-19: a multi-centric study of more than 1000 patients
}

Thomas Langer ${ }^{1,2}$, Matteo Brioni ${ }^{3}$, Amedeo Guzzardella ${ }^{4}$, Eleonora Carlesso ${ }^{4}$, Luca Cabrini ${ }^{5}$, Gianpaolo Castelli ${ }^{6}$, Francesca Dalla Corte ${ }^{7}$, Edoardo De Robertis ${ }^{8}$, Martina Favarato ${ }^{1}$, Andrea Forastieri ${ }^{9}$, Clarissa Forlini ${ }^{1,2}$, Massimo Girardis ${ }^{10}$, Domenico Luca Grieco ${ }^{11,12}$, Lucia Mirabella ${ }^{13}$, Valentina Noseda ${ }^{1}$, Paola Previtali ${ }^{2}$ Alessandro Protti ${ }^{7,14}$, Roberto Rona ${ }^{15}$, Francesca Tardini ${ }^{2}$, Tommaso Tonetti ${ }^{16}$, Fabio Zannoni ${ }^{3,4}$, Massimo Antonelli ${ }^{11,12}$, Giuseppe Foti ${ }^{1,15}$, Marco Ranieri ${ }^{16}$, Antonio Pesenti ${ }^{3,4}$, Roberto Fumagalli, ${ }^{1,2}$, Giacomo Grasselli, $34^{*}$ id and PRONA-COVID Group

\begin{abstract}
Background: Limited data are available on the use of prone position in intubated, invasively ventilated patients with Coronavirus disease-19 (COVID-19). Aim of this study is to investigate the use and effect of prone position in this population during the first 2020 pandemic wave.

Methods: Retrospective, multicentre, national cohort study conducted between February 24 and June 14, 2020, in 24 Italian Intensive Care Units (ICU) on adult patients needing invasive mechanical ventilation for respiratory failure caused by COVID-19. Clinical data were collected on the day of ICU admission. Information regarding the use of prone position was collected daily. Follow-up for patient outcomes was performed on July 15, 2020. The respiratory effects of the first prone position were studied in a subset of 78 patients. Patients were classified as Oxygen Responders if the $\mathrm{PaO}_{2} / \mathrm{FiO}_{2}$ ratio increased $\geq 20 \mathrm{mmHg}$ during prone position and as Carbon Dioxide Responders if the ventilatory ratio was reduced during prone position.

Results: Of 1057 included patients, mild, moderate and severe ARDS was present in 15, 50 and 35\% of patients, respectively, and had a resulting mortality of 25,33 and $41 \%$. Prone position was applied in $61 \%$ of the patients. Patients placed prone had a more severe disease and died significantly more ( $45 \%$ vs. $33 \%, p<0.001)$. Overall, prone position induced a significant increase in $\mathrm{PaO}_{2} / \mathrm{FiO}_{2}$ ratio, while no change in respiratory system compliance or ventilatory ratio was observed. Seventy-eight $\%$ of the subset of 78 patients were Oxygen Responders. Non-Responders had a more severe respiratory failure and died more often in the ICU (65\% vs. $38 \%, p=0.047$ ). Forty-seven $\%$ of patients were defined as Carbon Dioxide Responders. These patients were older and had more comorbidities; however, no difference in terms of ICU mortality was observed (51\% vs. 37\%, $p=0.189$ for Carbon Dioxide Responders and NonResponders, respectively).
\end{abstract}

\footnotetext{
*Correspondence: giacomo.grasselli@unimi.it

${ }^{3}$ Department of Anesthesia, Critical Care and Emergency, Fondazione

IRCCS Ca' Granda Ospedale Maggiore Policlinico, Via Francesco Sforza 35,

20122 Milan, Italy

Full list of author information is available at the end of the article
} permits use, sharing, adaptation, distribution and reproduction in any medium or format, as long as you give appropriate credit to the original author(s) and the source, provide a link to the Creative Commons licence, and indicate if changes were made. The images or other third party material in this article are included in the article's Creative Commons licence, unless indicated otherwise in a credit line to the material. If material is not included in the article's Creative Commons licence and your intended use is not permitted by statutory regulation or exceeds the permitted use, you will need to obtain permission directly from the copyright holder. To view a copy of this licence, visit http://creativecommons.org/licenses/by/4.0/. The Creative Commons Public Domain Dedication waiver (http://creativeco mmons.org/publicdomain/zero/1.0/) applies to the data made available in this article, unless otherwise stated in a credit line to the data. 
Conclusions: During the COVID-19 pandemic, prone position has been widely adopted to treat mechanically ventilated patients with respiratory failure. The majority of patients improved their oxygenation during prone position, most likely due to a better ventilation perfusion matching.

Trial registration: clinicaltrials.gov number: NCT04388670

Keywords: COVID-19, Mechanical ventilation, Prone positioning, Refractory hypoxemia

\section{Background}

At the end of 2019, an outbreak of pneumonia of unknown etiology started from Wuhan, Hubei, China and subsequently spread worldwide. Italy was hit at the end of February 2020 and, as of the end of July 2020, more than 250,000 infections and more than 35,000 deaths had been reported [1]. A novel beta-coronavirus, named Severe Acute Respiratory Syndrome Coronavirus 2 (SARS-COV-2), was identified as the cause of the epidemic [2], and the resulting disease was called Coronavirus Disease 2019 (COVID-19). COVID-19 has a broad spectrum of clinical presentations, ranging from asymptomatic to extremely severe forms. A significant proportion of infected subjects develops the acute respiratory distress syndrome (ARDS) [3, 4] and requires invasive mechanical ventilation and admission to an intensive care unit (ICU) $[4,5]$.

In patients developing refractory hypoxemia despite invasive mechanical ventilation, the application of rescue therapies such as extracorporeal gas exchange, inhaled nitric oxide and prone positioning is frequently required [6]. Previous experience in patients with moderate-tosevere ARDS from different causes showed that early application of prone position is associated with a significant survival benefit [7-9]. In patients with ARDS, prone positioning should favour the re-expansion of collapsed lung parenchyma in dorsal lung regions, and reduction in aeration in ventral ones, leading both to lung recruitment and more homogenous lung aeration. While distribution of ventilation is certainly influenced by the postural change, lung perfusion is usually considered less dependent on gravity $[10,11]$. Nevertheless, the net effect is usually a better ventilation-perfusion matching in prone position, resulting in improved gas exchange. Moreover, the more homogenous distribution of ventilation should reduce the risk of ventilator-induced lung injury.

Given the high number of COVID-19 patients with respiratory failure treated outside the ICU, there has been an increasing interest in the use of prone position in awake, spontaneously breathing patients [12-16]. On the contrary, limited data are available on the use of prone position in intubated, invasively ventilated patients $[17$, $18]$.

Aims of the present study are: (1) to describe the frequency of use of prone positioning and the clinical characteristics and outcomes of patients undergoing prone positioning in a large cohort of critically ill, mechanically ventilated patients with COVID-19; and (2) to describe, in a subgroup of patients, the pathophysiological effects of prone positioning.

\section{Methods}

Study design

This Italian multicentre, retrospective study of prospectively collected data was approved by the Ethical Committees of all participating centres (Promoting Centre's Ethical Committee: Comitato Etico Milano Area 2; protocol: 0008489; date of approval: March 20, 2020) and registered at clinicaltrials.gov (NCT04388670). The need for informed consent from individual patients was waived owing to the retrospective nature of the study.

All patients admitted between February 22, 2020, and June 14, 2020, inclusive for those days, to the COVID-19 ICUs of 24 Italian hospitals (see Additional file 1: Table E1 for the complete list) were screened for eligibility. Laboratory-confirmed SARS-CoV-2 infection, (i.e. positive result of real-time reverse transcriptase-polymerase chain reaction assay of nasal and pharyngeal swabs), and ICU admission for ARDS, defined by the Berlin criteria [19], constituted the inclusion criteria. Exclusion criteria were age $<18$ years, patients treated exclusively with noninvasive respiratory support and missing clinical data regarding the use of prone position. Clinical management (including mechanical ventilation setting and pharmacological therapies) followed the local treatment guidelines of each centre. The choice to position patients prone was at discretion of the attending physician.

The population of patients included in the analysis was subdivided in two groups according to the use of prone positioning: (1) PP group: patients who were turned prone at least once during their ICU stay; and (2) SP group: patients always treated in the supine position.

\section{Data collection}

An electronic case report form (REDCap electronic data capture tools) hosted at IRCCS Ca' Granda Ospedale Maggiore Policlinico was used for data collection. An extensive set of information regarding demographic and anthropometric data, comorbidities [20] and clinical data (severity scores [21-23], vital signs, type of respiratory 
support, use of prone positioning, respiratory parameters, laboratory tests including blood gas analysis) was collected on the day of admission to the ICU. Relevant clinical and laboratory data, including information regarding the use of prone positioning in the prior $24 \mathrm{~h}$, were then collected daily until ICU discharge or patient death.

Finally, the following patient outcomes were recorded: ICU and hospital survival, ICU and hospital length of stay (LOS), duration of invasive mechanical ventilation. The final date of follow-up for patient outcomes were July $15,2020$.

\section{Effect of prone positioning on respiratory mechanics and gas exchange}

To assess the physiologic effects of pronation, a subgroup of 78 patients who underwent prone positioning in two of the participating hospitals (Grande Ospedale Metropolitano Niguarda and Fondazione IRCCS $\mathrm{Ca}^{\prime}$ Granda Ospedale Maggiore Policlinico, both in Milan) was investigated at three different time points: (1) prior to the first pronation (Baseline); (2) during the last hour of the first session of prone ventilation (Prone); and (3) within $4 \mathrm{~h}$ after turning the patients back to supine position (Supine). At each time-point, end-inspiratory and end-expiratory airway occlusion manoeuvres were performed and arterial blood gases analyzed to obtain the following variables: compliance of the respiratory system ( $\mathrm{Crs}$, calculated as the ratio between tidal volume and airway driving pressure); ratio between partial pressure of oxygen $\left(\mathrm{PaO}_{2}\right)$ and inspired fraction of oxygen $\left(\mathrm{FiO}_{2}\right),-\mathrm{PaO}_{2} / \mathrm{FiO}_{2}$ ratio; corrected minute ventilation [24] and ventilatory ratio [25]. Patients were defined as " $\mathrm{O}_{2}$-Responders", if they had an increase in the $\mathrm{PaO}_{2} /$ $\mathrm{FiO}_{2}$ ratio of $\geq 20 \mathrm{mmHg}$ during prone ventilation as compared to baseline values in supine position [26, 27]. Moreover, patients were defined as Responders in terms of carbon dioxide $\left(\mathrm{CO}_{2}\right)$ clearance, "CO${ }_{2}$-Responders", if their ventilatory ratio was reduced during prone ventilation, as compared to baseline values in supine position, i.e. if the difference between ventilatory ratio in prone position and ventilatory ratio at baseline $(\Delta \mathrm{VR})$ was $<0$.

\section{Statistical analysis}

Continuous variables are presented as mean with standard deviation (SD) or median and interquartile range (IQR). Categorical variables are expressed as frequencies (percentages).

Mann-Whitney rank sum test was used to compare nonparametric continuous variables between study groups. $\chi^{2}$ or Fisher exact test was used for categorical variables, as appropriate.
Differences among time-points were tested by one-way ANOVA for repeated measures or Friedman Repeated Measures Analysis of Variance on Ranks, as appropriate. Pairwise multiple comparisons were tested using Tukey's test. Differences among tertiles of pre-pronation driving pressure were tested by one-way ANOVA on ranks. Pairwise multiple comparisons were tested using Dunn's Method. All statistical tests were 2-tailed, and statistical significance was defined as a $p$ value below 0.05. Analyses were performed using SAS 9.4 (SAS Institute Inc., Cary, NC, USA), STATA computer software, version 16.0 (StataCorp LLC) and SigmaPlot 12.0 (Systat Software Inc., San Jose, CA).

\section{Results}

One thousand three hundred twenty-six patients fulfilled the inclusion criteria. After exclusions (one patient aged $<18$ years, 123 patients with missing information regarding the use of prone position and 145 patients who were never intubated), 1057 patients were analyzed (Flowchart reported in Additional file 1: Fig. E1).

Table 1 summarizes the patients' demographic and clinical characteristics at ICU admission and their clinical outcomes. Additional information is reported in Additional file 1, Table E2. Most patients were male (79\%), median age was 63 [55-69] years, and median body mass index was 28 [25-31] kg/m ${ }^{2}$. Median SAPS II and SOFA score at ICU admission were 36 [30-44] and 4 [3-4], respectively. Eighty-four \% of patients were intubated and mechanically ventilated at ICU admission or during the first day in ICU. ARDS severity was mild in 15\%, moderate in $50 \%$ and severe in $35 \%$ of the cases. Median $\mathrm{PaO}_{2} /$ $\mathrm{FiO}_{2}$ ratio, respiratory rate, tidal volume/predicted body weight and plateau airway pressure of mechanically ventilated patients were $120 \mathrm{mmHg}$ [88-173], 20 [18-25] breaths/min, 7.0 [6.3-7.8] mL/kg and 24 [22-27] $\mathrm{cmH}_{2} \mathrm{O}$, respectively. As of July 15, 2020, 677 (64\%) patients had been discharged from the ICU and 374 (36\%) had died (6 missing data). Mortality increased significantly with increasing severity of ARDS $(25,33,41 \%, p=0.004$, for mild, moderate and severe ARDS, respectively). The median ICU length of stay was 16 [10-28] days for patients discharged from the ICU, and 12 [6-20] days for those who died in the ICU.

\section{Use of prone positioning and differences between pronated and non-pronated patients}

Six-hundred and forty-eight patients (61\% of the overall population) were placed in prone position at least once during their stay in the ICU (PP Group), while 409 patients (39\% of the overall population) were always treated in the supine position (SP Group). The frequency of use of prone positioning increased with ARDS 
Table 1 Patients' characteristics at admission in ICU and outcome

\begin{tabular}{|c|c|c|c|c|}
\hline Variables & Overall $(n=1057)$ & Non-proned $(n=409,39 \%)$ & Proned $(n=648,61 \%)$ & $p$ value \\
\hline Males, no. (\%) & $831(79)$ & $317(78)$ & $514(79)$ & 0.483 \\
\hline Age (years) & $63(55-69)$ & $63(55-69)$ & $63(55-69)$ & 0.773 \\
\hline BMI $\left(\mathrm{kg} / \mathrm{m}^{2}\right)$ & $28(25-31)$ & $27(25-31)$ & $28(25-31)$ & 0.023 \\
\hline SOFA score & $4(3-5)$ & $4(3-4)$ & $4(3-5)$ & $<0.001$ \\
\hline APACHE II score & $10(7-13)$ & $9(7-13)$ & $10(8-13)$ & 0.013 \\
\hline Intubated, no. $(\%)^{\mathrm{a}}$ & $892(84)$ & $351(86)$ & $541(84)$ & 0.309 \\
\hline Respiratory Rate (breaths/min) & $20(18-25)$ & $20(16-24)$ & $20(18-25)$ & $<0.001$ \\
\hline $\mathrm{FiO}_{2}(\%)^{\mathrm{b}}$ & $70(60-90)$ & $60(50-80)$ & $80(60-90)$ & $<0.001$ \\
\hline $\operatorname{PEEP}\left(\mathrm{cmH}_{2} \mathrm{O}\right)^{\mathrm{b}}$ & $12(10-14)$ & $12(10-14)$ & $12(10-14)$ & $<0.001$ \\
\hline $\mathrm{PaO}_{2} / \mathrm{F}_{1} \mathrm{O}_{2}$ ratio ${ }^{\mathrm{b}}$ & $120(88-173)$ & $145(107-197)$ & $108(81-148)$ & $<0.001$ \\
\hline \multicolumn{5}{|l|}{ ARDS severity, no. $(\%)^{b}$} \\
\hline Mild & $128(15)$ & $76(23)$ & $52(10)$ & \multirow[t]{3}{*}{$<0.001$} \\
\hline Moderate & $426(50)$ & $183(56)$ & $243(46)$ & \\
\hline Severe & $298(35)$ & $69(21)$ & $229(44)$ & \\
\hline Tidal volume/PBW $(\mathrm{mL} / \mathrm{kg})^{\mathrm{b}}$ & $7.0(6.3-7.8)$ & $7.1(6.3-7.9)$ & $7.0(6.2-7.8)$ & 0.140 \\
\hline Plateau pressure $\left(\mathrm{cmH}_{2} \mathrm{O}\right)^{\mathrm{b}}$ & $24(22-27)$ & $24(21-26)$ & $25(22-28)$ & $<0.001$ \\
\hline Driving pressure $\left(\mathrm{cmH}_{2} \mathrm{O}\right)^{\mathrm{b}}$ & $12(9-14)$ & $12(9-13)$ & $12(9-14)$ & 0.120 \\
\hline $\begin{array}{l}\text { Respiratory system compliance (mL/ } \\
\left.\mathrm{CmH}_{2} \mathrm{O}\right)^{\mathrm{b}}\end{array}$ & $40(33-50)$ & $42(35-50)$ & $38(32-50)$ & 0.035 \\
\hline $\mathrm{pH}$ & $7.39(7.32-7.46)$ & $7.40(7.33-7.46)$ & $7.39(7.31-7.45)$ & 0.220 \\
\hline $\mathrm{PaO}_{2}(\mathrm{mmHg})$ & $80(67-101)$ & $86(70-108)$ & $77(65-97)$ & $<0.001$ \\
\hline $\mathrm{PaCO}_{2}(\mathrm{mmHg})$ & $43(36-52)$ & $43(37-51)$ & $43(36-53)$ & 0.710 \\
\hline Ventilatory ratio ${ }^{b}$ & $1.7(1.4-2.2)$ & $1.7(1.3-2.1)$ & $1.8(1.4-2.2)$ & 0.061 \\
\hline LDH (units/L) & $479(359-640)$ & $424(324-593)$ & $507(392-667)$ & $<0.001$ \\
\hline D-dimer (ng/mL) & $1492(608-4602)$ & $1190(520-3470)$ & $1730(690-6576)$ & 0.001 \\
\hline Ferritine $(\mathrm{ng} / \mathrm{mL})$ & $1408(811-2399)$ & $1214(668-1903)$ & $1552(1031-2491)$ & 0.003 \\
\hline ICU mortality, no. (\%) & $374(36)$ & $112(28)$ & $262(41)$ & $<0.001$ \\
\hline Hospital mortality, no. (\%) & $405(41)$ & $127(33)$ & $278(45)$ & $<0.001$ \\
\hline ICU LOS (days) & $15(9-25)$ & $12(7-21)$ & $16(11-28)$ & $<0.001$ \\
\hline Hospital LOS (days) & $29(17-46)$ & $26(16-40)$ & $30(17-49)$ & 0.008 \\
\hline Mechanical ventilation (days) & $14(8-26)$ & $10(6-19)$ & $16(10-30)$ & $<0.001$ \\
\hline
\end{tabular}

Data are expressed either as median [interquartile range] or as frequency (percentage)

$\mathrm{BMI}=$ Body Mass Index; SOFA = Sequential Organ Failure Assessment; APACHE II = Acute Physiologic Assessment and Chronic Health Evaluation II; FiO ${ }_{2}=$ Inspired fraction of oxygen; $\mathrm{PEEP}=$ Positive End-Expiratory Pressure; $\mathrm{PBW}$ : Predicted Body Weight; $\mathrm{PaO}_{2}$ : partial pressure of oxygen in arterial blood; $\mathrm{PaCO}_{2}$ : partial pressure of carbon dioxide in arterial blood; LDH: lactate dehydrogenase; LOS = Length of stay

a Patients intubated same day of ICU admission

b Values refer to patients intubated on the same day of ICU admission

severity (52/128 (44\%), 243/426 (57\%) and 229/298 (77\%), $p<0.001$, in mild, moderate and severe ARDS, respectively). Prone positioning was first applied 2 [1-4] days after ICU admission, and a median of 3 [1-4] pronation sessions per patient was performed.

Table 1 outlines the principal differences between the two groups (additional information is summarized in Additional file 1, Table E2). No difference in comorbidities was observed (Charlson Comorbidity Index 2 [1-3] vs. $2[1-3], p=0.165)$. Patients in the PP group had significantly more severe respiratory disease, as suggested by a higher percentage of severe ARDS ( $44 \%$ vs. $21 \%$, $p<0.001)$ and a lower percentage of mild ARDS (10 vs. $23 \%, p<0.001)$. Respiratory rate, positive end-expiratory pressure (PEEP), $\mathrm{FiO}_{2}$ and Plateau pressure were significantly higher, while respiratory system compliance, $\mathrm{PaO}_{2} / \mathrm{FiO}_{2}$ ratio and arterial $\mathrm{pH}$ at ICU admission were significantly lower in the PP group. In addition, biochemical markers of inflammation and disease severity, such as LDH, D-dimers and ferritin, were consistently higher in patients of the PP Group. Patients of the PP group had higher severity scores: SOFA (4 [3-5] vs. 4 [3-4], $p<0.001)$ and APACHE II scores (10 [8-13] vs. 9 [7-13], $p<0.001)$. Finally, ICU mortality and length of stay, 
length of mechanical ventilation and hospital mortality and length of stay were all significantly worse in patients in the PP group.

\section{Physiological effects of prone position}

In the subgroup of 78 patients, median duration of the first pronation was 18.5 [16-22] hours. Respiratory system compliance did not change significantly with the change in body position (Fig. 1a). Similarly, on average, prone positioning had no significant effect on ventilatory ratio (Fig. 1c). Overall, prone positioning led to a significant increase in $\mathrm{PaO}_{2} / \mathrm{FiO}_{2}$ ratio, which was followed by a subsequent significant decrease with re-supination (Fig. 1b). On average, $\mathrm{PaO}_{2} / \mathrm{FiO}_{2}$ ratio after re-supination remained significantly higher as compared to baseline values. Table 2 summarizes the physiologic variables at the three different time points selected for the analysis.

\section{$\mathrm{O}_{2}$-responders versus $\mathrm{O}_{2}$-non-responders}

Sixty-one out of 78 patients $(78 \%)$ had an increase in $\mathrm{PaO}_{2} / \mathrm{FiO}_{2}$ ratio $\geq 20 \mathrm{mmHg}$ (median increase 68 [42-117] $\mathrm{mmHg}$ ) and where therefore defined as $\mathrm{O}_{2}$-Responders. Seventeen $(22 \%)$ patients had an increase in $\mathrm{PaO}_{2} / \mathrm{FiO}_{2}$ ratio $<20 \mathrm{mmHg}$ (median variation $3[1-12] \mathrm{mmHg}$ ) and were therefore classified as $\mathrm{O}_{2}$-Non-Responders. Individual variations in $\mathrm{PaO}_{2} / \mathrm{FiO}_{2}$ ratio due to the change in body position in $\mathrm{O}_{2}$-Responders and $\mathrm{O}_{2}$-Non-Responders are reported in Fig. 2a,
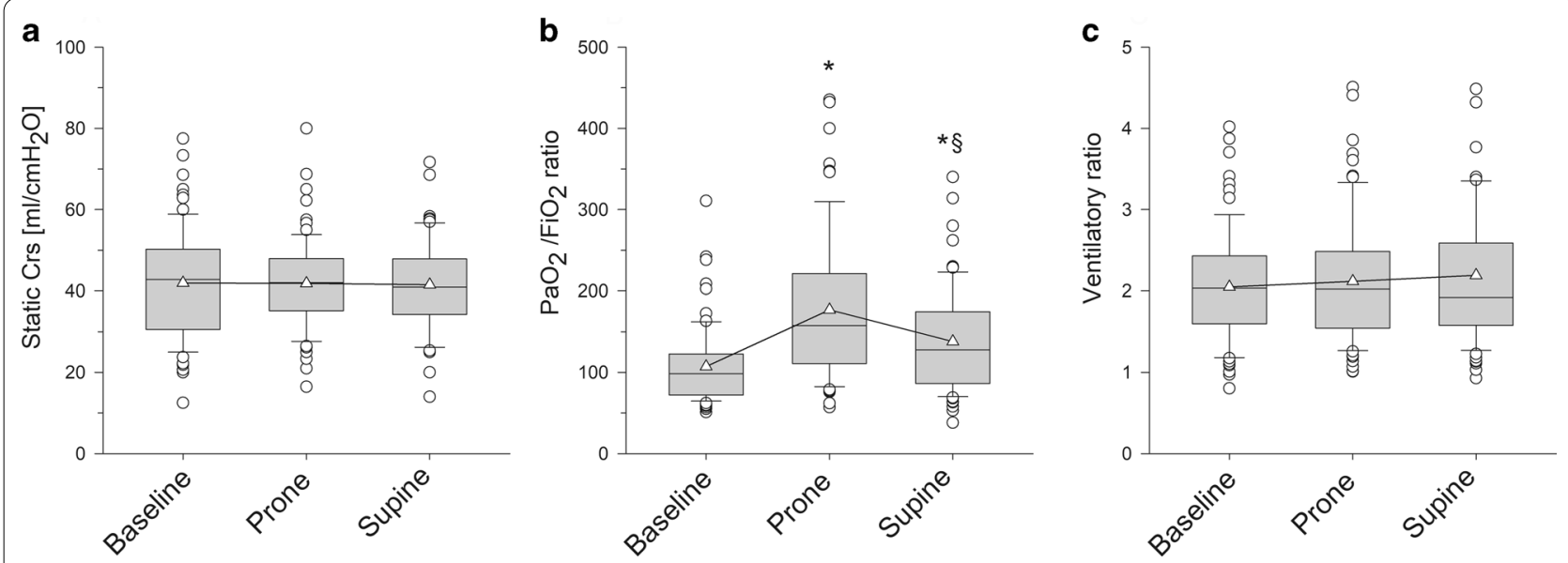

Fig. 1 Physiological parameters' changes during the first session of prone positioning

Table 2 Physiologic variables before, during and after prone positioning $(n=78)$

\begin{tabular}{|c|c|c|c|c|}
\hline Variables & Baseline & Prone & Supine & $p$ value \\
\hline $\operatorname{PEEP}\left(\mathrm{cmH}_{2} \mathrm{O}\right)$ & $14(12-15)$ & $14(12-15)$ & $14(12-15)$ & 0.679 \\
\hline $\mathrm{FiO}_{2}(\%)$ & $70(60-90)$ & $60(50-70)^{\mathrm{a}}$ & $60(45-80)^{\mathrm{a}}$ & $<0.001$ \\
\hline Tidal volume/PBW (mL/kg) & $6.8(6.1-7.6)$ & $6.7(6.2-7.3)$ & $6.8(6.2-7.4)$ & 0.619 \\
\hline Driving pressure $\left(\mathrm{cmH}_{2} \mathrm{O}\right)$ & $11(10-14)$ & $11(10-14)$ & $11(9-14)$ & 0.147 \\
\hline Plateau pressure $\left(\mathrm{cmH}_{2} \mathrm{O}\right)$ & $25(22-28)$ & $24(23-27)$ & $24(23-28)$ & 0.324 \\
\hline Respiratory rate (breaths/min) & $20(18-22)$ & $22(20-24)^{a}$ & $22(20-24)^{\mathrm{a}}$ & $<0.001$ \\
\hline Minute ventilation (L/min) & $9.4(7.7-11.0)$ & $9.6(8.3-11.2)$ & $9.9(8.2-11.2)$ & 0.052 \\
\hline Corrected minute ventilation ( $\mathrm{L} / \mathrm{min})$ & $12.6(9.8-15.2)$ & $12.6(9.5-15.7)$ & $12.2(10.3-14.9)$ & 0.881 \\
\hline $\mathrm{PaCO}_{2}(\mathrm{mmHg})$ & $53(45-60)$ & $53(43-59)$ & $52(46-60)$ & 0.302 \\
\hline Respiratory system Compliance $\left(\mathrm{mL} / \mathrm{cmH}_{2} \mathrm{O}\right)$ & $43(31-50)$ & $42(35-48)$ & $41(34-48)$ & 0.943 \\
\hline $\mathrm{PaO}_{2} / \mathrm{FiO}_{2}$ ratio & $98(72-121)$ & $158(112-220)^{a}$ & $128(87-174)^{a, b}$ & $<0.001$ \\
\hline Ventilatory ratio & $2.0(1.6-2.4)$ & $2.0(1.5-2.5)$ & $1.9(1.6-2.5)$ & 0.881 \\
\hline
\end{tabular}

Data are expressed as median (interquartile range)

$\mathrm{PEEP}=$ Positive End-Expiratory Pressure; $\mathrm{FiO}_{2}=$ fraction of inspired oxygen; $\mathrm{PBW}=$ Predicted Body Weight; $\mathrm{PaCO}_{2}=$ partial pressure of carbon dioxide in arterial blood a $p<0.05$ versus baseline

${ }^{b} p<0.05$ versus prone 
b, respectively. Table 3 summarizes the differences between $\mathrm{O}_{2}$-Responders and $\mathrm{O}_{2}$-Non-Responders (for additional information see Additional file 1, Table E3). Demographics, comorbidities and admission severity scores were similar between $\mathrm{O}_{2}$-Responders and $\mathrm{O}_{2}$-Non-Responders.

Notably, at ICU admission, driving pressure (14 [12$15]$ vs. 12 [8-13] $\left.\mathrm{cmH}_{2} \mathrm{O}, p=0.022\right)$, plateau pressure (27 [24-28] vs. 24 [22-27] $\left.\mathrm{cmH}_{2} \mathrm{O}, p=0.043\right)$ and respiratory system compliance (34 [30-45] vs. 45 [34-56] $\mathrm{mL} / \mathrm{cmH}_{2} \mathrm{O}, \quad p=0.018$ ) were significantly different between $\mathrm{O}_{2}$-Responders and $\mathrm{O}_{2}$-Non-Responders. Moreover, prior to first pronation, baseline driving pressure (14 [11-16] vs. 11 [10-13] $\left.\mathrm{cmH}_{2} \mathrm{O}, p=0.036\right)$, respiratory rate $(22[20-24]$ vs. $20[18-22]$ breaths per minute, $p=0.014$ ), $\mathrm{PaCO}_{2}$ (58 [50-67] vs. 52 [45-60] $\mathrm{mmHg}$, $p=0.092)$ and ventilatory ratio $(2.2[1.9-2.7]$ vs. 1.9 [1.6-2.2], $p=0.014)$ were higher in $\mathrm{O}_{2}$-Non-Responders, while Respiratory System Compliance (33 [26-45] vs. $\left.44[33-51] \mathrm{mL} / \mathrm{cmH}_{2} \mathrm{O}, p=0.029\right)$, and $\mathrm{pH}(7.33$ [7.31-7.38] vs. 7.37 [7.34-7.40], $p=0.041$ ) were lower. When dividing the overall population in tertiles of prepronation driving pressure, a significantly different variation in $\mathrm{PaO}_{2}, \mathrm{FiO}_{2}$ ratio was observed, with patients with lower driving pressures having greater increase in $\mathrm{PaO}_{2} / \mathrm{FiO}_{2}$ ratio (Additional file 1: Fig. E2). ICU mortality $(11 / 17,65 \%$ vs. $23 / 61,38 \%, p=0.047)$ was higher in $\mathrm{O}_{2}$-Non-Responders. Similar results were observed using a $10-20 \%$ increase in $\mathrm{PaO}_{2} / \mathrm{FiO}_{2}$ ratio as cut off $(8 / 11,72 \%$ vs. $26 / 67,39 \%, p=0.035$ at $10 \%$ increase in $\mathrm{PaO}_{2} / \mathrm{FiO}_{2}$ ratio and $9 / 15,60 \%$ vs. $25 / 63,40 \%, p=0.154$ at $20 \%$ increase in $\mathrm{PaO}_{2} / \mathrm{FiO}_{2}$ ratio).

\section{$\mathrm{CO}_{2}$-responders versus $\mathrm{CO}_{2}$-non responders}

Thirty-seven out of 78 patients (47\%) reduced their ventilatory ratio during prone position (median $\triangle \mathrm{VR}-0.21$ [ -0.36 to -0.10$])$ and where therefore defined as $\mathrm{CO}_{2}$ Responders. In 41 (53\%) patients, the ventilatory ratio did not change or increased in prone position (median $\Delta \mathrm{VR}$ 0.28 [0.09-0.54]): These patients were therefore defined as $\mathrm{CO}_{2}$-Non Responders. Differences between Responders and Non-Responders in terms of $\mathrm{CO}_{2}$ clearance are summarized in Additional file 1, Table E4. In summary, no differences were observed in the two populations, except for older age (65 [59-70] years vs. 56 [50-64] years, $p=0.005)$ and higher prevalence of hypertension $(68 \%$ vs. $34 \%, p=0.003)$ in $\mathrm{CO}_{2}$-Non Responders. ICU mortality did not differ between the two groups $(19 / 37,51 \%$ vs. $15 / 41,37 \%, p=0.189$ in $\mathrm{CO}_{2}$-Responders and $\mathrm{CO}_{2}$-NonResponders, respectively).

\section{Discussion}

In this national, multicentre, retrospective observational study performed in the ICUs of 24 Italian hospitals during the first peak of the 2020 COVID-19 pandemic, we investigated the use of prone positioning in a cohort of 1057 critically ill, invasively ventilated patients with respiratory failure due to COVID-19. We also analyzed the pathophysiologic respiratory effects of this manoeuvre in a subset of 78 patients. A major finding of our study is that prone positioning was applied very frequently, significantly more often than previously reported in other populations of ARDS patients [28, 29]. Indeed, $61 \%$ of our patients underwent at least one pronation session during their ICU stay, as compared to $8 \%$ of the patients enrolled in the LUNG SAFE study. The frequency of use of prone positioning increased with increasing ARDS
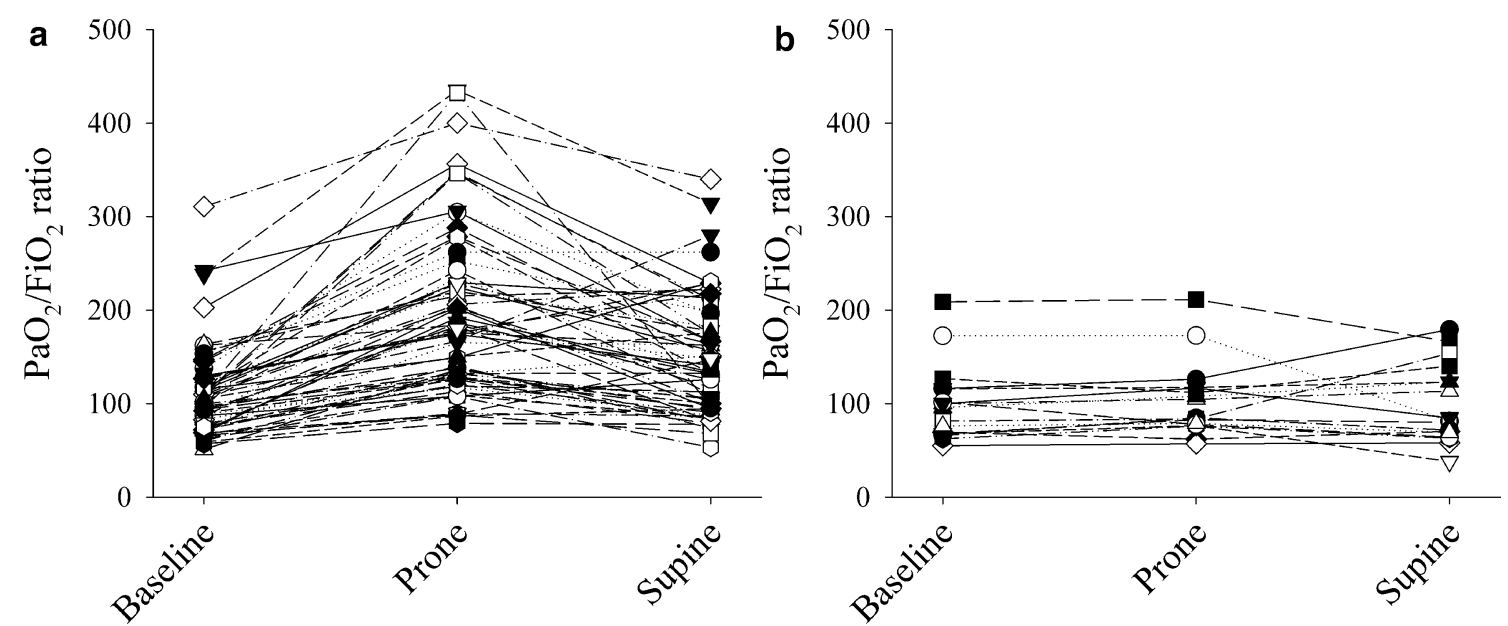

Fig. 2 Individual variations in $\mathrm{PaO}_{2} / \mathrm{FiO}_{2}$ ratio in Responders and Non-Responders during the first session of prone positioning 
Table 3 Patients' characteristics at admission in ICU and outcome divided by $\mathrm{O}_{2}$-Responders versus $\mathrm{O}_{2}$-Non-Responders

\begin{tabular}{|c|c|c|c|c|}
\hline Variables & Overall $(n=78)$ & $\begin{array}{l}\mathrm{O}_{2} \text {-non-responders }(n=17 \\
22 \%)\end{array}$ & $\mathrm{O}_{2}$-responders $(n=61,78 \%)$ & $p$ value \\
\hline Males, no. (\%) & $61(78)$ & $13(77)$ & $48(79)$ & 0.845 \\
\hline Age (years) & $62(51-68)$ & $56(51-66)$ & $62(52-68)$ & 0.389 \\
\hline BMI $\left(\mathrm{kg} / \mathrm{m}^{2}\right)$ & $27(25-31)$ & $26(24-31)$ & $27(26-31)$ & 0.670 \\
\hline SOFA score & $4(3-5)$ & $4(3-5)$ & $4(4,5)$ & 0.294 \\
\hline APACHE II score & $10(8-12)$ & $11(8-14)$ & $10(8-12)$ & 0.620 \\
\hline Intubated, no. (\%) & $75(96)$ & $16(94)$ & $59(97)$ & 0.622 \\
\hline Respiratory rate (breaths/min) & $20(18-22)$ & $19(18-22)$ & $20(17-22)$ & 0.813 \\
\hline $\mathrm{FiO}_{2}(\%)^{\mathrm{b}}$ & $75(60-90)$ & $80(60-88)$ & $70(60-90)$ & 0.839 \\
\hline $\operatorname{PEEP}\left(\mathrm{cmH}_{2} \mathrm{O}\right)^{\mathrm{b}}$ & $14(12-15)$ & $14(11-14)$ & $14(12-15)$ & 0.662 \\
\hline $\mathrm{PaO}_{2} / \mathrm{F}_{1} \mathrm{O}_{2}$ ratio ${ }^{\mathrm{b}}$ & $111(83-164)$ & $99(72-150)$ & $114(85-168)$ & 0.419 \\
\hline \multicolumn{5}{|l|}{ ARDS severity, no. (\%) ${ }^{b}$} \\
\hline Mild & $10(13)$ & $2(13)$ & $8(14)$ & \multirow[t]{3}{*}{0.721} \\
\hline Moderate & $34(45)$ & $6(38)$ & $28(48)$ & \\
\hline Severe & $31(41)$ & $8(50)$ & $23(39)$ & \\
\hline Tidal volume/PBW $(\mathrm{mL} / \mathrm{kg})^{b}$ & $7.0(6.4-7.8)$ & $7.2(6.2-7.9)$ & $7.0(6.4-7.8)$ & 0.707 \\
\hline Plateau pressure $\left(\mathrm{cmH}_{2} \mathrm{O}\right)^{\mathrm{b}}$ & $25(22-27)$ & $27(24-28)$ & $24(22-27)$ & 0.043 \\
\hline Driving pressure $\left(\mathrm{cmH}_{2} \mathrm{O}\right)^{\mathrm{b}}$ & $12(9-14)$ & $14(12-15)$ & $12(8-13)$ & 0.022 \\
\hline $\begin{array}{l}\text { Respiratory system compliance (mL/ } \\
\left.\mathrm{CmH}_{2} \mathrm{O}\right)^{\mathrm{b}}\end{array}$ & $42(32-53)$ & $34(30-45)$ & $45(34-56)$ & 0.018 \\
\hline $\mathrm{pH}$ & $7.36(7.31-7.41)$ & $7.33(7.29-7.42)$ & $7.37(7.32-7.41)$ & 0.244 \\
\hline $\mathrm{PaO}_{2}(\mathrm{mmHg})$ & 78 (70-95) & $76(68-90)$ & $80(70-99)$ & 0.443 \\
\hline $\mathrm{PaCO}_{2}(\mathrm{mmHg})$ & $47(40-56)$ & $50(39-58)$ & $47(41-55)$ & 0.417 \\
\hline Ventilatory ratio & $1.8(1.4-2.0)$ & $1.8(1.4-2.5)$ & $1.8(1.4-2.0)$ & 0.345 \\
\hline LDH (units/L) & $414(307-490)$ & $418(329-485)$ & $400(301-490)$ & 0.620 \\
\hline ICU mortality, no. (\%) & $34(44)$ & $11(65)$ & $23(38)$ & 0.047 \\
\hline Hospital mortality, no. (\%) & $34(44)$ & $11(65)$ & $23(38)$ & 0.047 \\
\hline ICU LOS (days) & $18(11-34)$ & $18(12-47)$ & $19(11-33)$ & 0.981 \\
\hline Hospital LOS (days) & $36(17-58)$ & $32(14-47)$ & $39(21-61)$ & 0.295 \\
\hline Mechanical ventilation (days) & $19(11-35)$ & $16(11-35)$ & $19(11-35)$ & 0.832 \\
\hline
\end{tabular}

Data are expressed either as median (interquartile range) or as frequency (percentage)

$\mathrm{BMI}=$ Body Mass Index; SOFA = Sequential Organ Failure Assessment; APACHE II=Acute Physiologic Assessment and Chronic Health Evaluation II; FiO ${ }_{2}=$ Inspired fraction of oxygen; PEEP = Positive End-Expiratory Pressure; $\mathrm{PBW}$ : Predicted Body Weight; $\mathrm{PaO}_{2}$ : partial pressure of oxygen in arterial blood; PaCO $\mathrm{O}_{2}$ : partial pressure of carbon dioxide in arterial blood; LDH: lactate dehydrogenase; LOS = Length of stay

a Patients intubated same day of ICU admission

b Values refer to patients intubated on the same day of ICU admission

severity. Notably, 77\% of COVID-19 patients with severe ARDS underwent prone positioning, as compared to the $16 \%$ of those with severe ARDS in the LUNG SAFE cohort. Of note, prone position was also frequently applied in patients with mild and moderate ARDS at ICU admission.

Changing body position from supine to prone (or vice versa) requires dedicated and experienced personnel. Moreover, the manoeuvre frequently requires incremental dosages of sedatives and muscle relaxants [30] and may lead to hemodynamic instability. In addition, it is associated with an increased risk of device displacement and pressure ulcers [31]. It is important to underline that in our study, the decision to turn the patients in prone position was at the discretion of the ICU team, i.e. there were no pre-specified criteria for the application of this rescue manoeuvre. Due the overwhelming number of critically ill patients requiring ICU admission, the ICU bed capacity of our hospitals had to be rapidly increased [32]. Therefore, many physicians and nurses usually working outside the ICU environment and even doctors from other specialities were recruited to allow the surge in ICU capacity. This of course reduced the expertise of the whole ICU staff. Our data clearly show that prone positioning was applied to patients with more severe disease, mainly as a rescue therapy (Table 1). Consequently, 
the worse clinical outcomes of patients undergoing prone positioning can be explained by the higher disease severity. However, given the retrospective nature of the study, we cannot draw any conclusions on the efficacy of prone position in terms of outcome.

Another important finding, resulting from the physiological sub-study, is that, on average, the $\mathrm{PaO}_{2} / \mathrm{FiO}_{2}$ ratio increased significantly from 98 [72-212] to 158 [112220] $\mathrm{mmHg}, p<0.001$ (Fig. 1b) during the first pronation session. Moreover, while the $\mathrm{PaO}_{2} / \mathrm{FiO}_{2}$ ratio dropped with re-supination, as previously observed [33, 34], values after re-supination remained significantly higher than baseline values (128 [87-174] vs. 98 [72-212], $p<0.05)$.

The findings of the physiologic sub-study (Table 2) thus suggest that the main mechanism inducing an improvement in oxygenation during the first pronation of COVID-19 patients with ARDS is the improvement of the ventilation-perfusion matching, possibly favoured by a redistribution of flow from dorsal to ventral lung areas. Indeed, the lack of improvement of respiratory system compliance with the change in body position (Fig. 1a) suggests that lung recruitment was not the major mechanism. This hypothesis is also suggested by the fact that patients with lower driving pressure/higher respiratory system compliance and thus higher lung volumes, had, on average, greater increases in $\mathrm{PaO}_{2} / \mathrm{FiO}_{2}$ ratio (Fig. E2). We observed a modest, though significant increase in set respiratory rate and a resulting trend toward higher minute ventilations during prone positioning (Table 2). However, we did not observe a significant variation of the ventilatory ratio, a proxy of dead space and efficiency in $\mathrm{CO}_{2}$ removal (Fig. 1c). Taken together, these results suggest that $\mathrm{CO}_{2}$ production somehow increased during prone position, requiring an increase in minute ventilation to maintain stable $\mathrm{PaCO}_{2}$ values.

We used an increase in $\mathrm{PaO}_{2} / \mathrm{FiO}_{2}$ ratio during pronation of at least $20 \mathrm{mmHg}$ as cut-off to define the response to prone position in terms of oxygenation. Using this definition, $78 \%$ of the studied patients were considered " $\mathrm{O}_{2}$-Responders". There are no universally applied criteria to define the response to prone position, however, when looking at the literature using the same cut-off [26, 27], the percentage of patients with COVID-19-induced ARDS that responded to prone position seems similar to the percentage of the "general" ARDS population [26].

When analyzing the differences between $\mathrm{O}_{2}$-Responders and Non-Responders, we observed that, despite similar comorbidities and baseline severity scores, respiratory failure was on average more severe in $\mathrm{O}_{2}$-Non-Responders (Table 3). Indeed, Non-Responders had higher driving pressure and ventilatory ratio, suggesting a higher extension of lung dysfunction and a lower efficiency of gas exchange. In the ARDS literature, several studies did not find a different mortality between Responders and Non-Responders in terms of oxygenation [26, 27], while a recent study performed on ARDS, non-COVID patients, suggested that improved oxygenation after prone positioning might be a predictor of survival [35]. Also in our study performed in COVID-19 ARDS patients, we found that the mortality of $\mathrm{O}_{2}$-Non-Responders was significantly higher as compared to Responders (65\% vs. $38 \%$, $p=0.039$ ).

In order to evaluate the response to pronation in terms of $\mathrm{CO}_{2}$ clearance, we analyzed the variations in ventilatory ratio. Also in this case, there is no universally applied criteria to define $\mathrm{CO}_{2}$-Responders, and several cut-offs of absolute changes in partial pressure of $\mathrm{CO}_{2}\left(\mathrm{PCO}_{2}\right)$ during prone position have been previously used [26, 36-38]. The variation in $\mathrm{PCO}_{2}$ is used as a proxy of the efficiency of the system to eliminate $\mathrm{CO}_{2}$, i.e. pulmonary dead space fraction. Of course, this proxy can be evaluated only if the ventilatory settings do not change during prone position and, ideally, if the $\mathrm{CO}_{2}$ production is stable. We recorded a significant increase in respiratory rate and thus minute ventilation during prone position and therefore could not use the variation in $\mathrm{PCO}_{2}$ as a proxy of dead space variation. We therefore used a variation in the ventilatory ratio to differentiate between $\mathrm{CO}_{2}$-Responders and Non-Responders. In this exploratory analysis, $\mathrm{CO}_{2}$-NonResponders were found to be older and with more comorbidities; however, no significant difference in outcome was observed.

\section{Limitations}

The retrospective observational nature of the study is a clear limitation of our study. As already discussed, the decision to place the patient in prone position was at discretion of the attending physicians and the general clinical patient management was not standardized among centres. The comparison between the two groups gives therefore useful information about the decision-making process of Italian doctors caring for severely ill COVIDpatients during the first wave of the 2020 COVID pandemic. On the contrary, the comparison does not provide information about the efficacy of pronation in terms of outcome. In addition, we have not collected information regarding complications related to prone positioning. A certain rate of complications usually occurs during prone position. It is conceivable that the rate might be higher in the specific context of a pandemic surge. Regarding the physiologic sub-study, the absence of information of partitioned respiratory mechanics is certainly a limitation. Nevertheless, the fact that the respiratory system compliance did not change in the 3 time-points suggests that lung recruitment did not play a significant role during the first pronation. Moreover, the limited number of patients 
included in the physiologic sub-study limits the soundness of the observed differences between Responders and Non-Responders, both in terms of oxygenation and carbon dioxide clearance.

\section{Conclusions}

During the most intense months of the first wave of 2020 COVID-19 pandemic in Italy, critically ill, intubated and mechanically ventilated patients with ARDS were frequently placed in prone position. The more severe the respiratory failure, the more frequent the use of this rescue therapy. Placing the patients in prone position has the main purpose of reducing the injurious effects of mechanical ventilation. In addition, it is a cheap and effective manoeuvre, able to improve oxygenation in the vast majority of patients with respiratory failure due to COVID-19. In this population, the main mechanisms responsible for the improved oxygenation seems to be the improvement of the ventilation/perfusion matching.

\section{Abbreviations}

APACHE II: Acute Physiology and Chronic Health Disease Classification System II; ARDS: Acute respiratory distress syndrome; COVID-19: Coronavirus Disease 2019; $\mathrm{FiO}_{2}$ : Inspired fraction of oxygen; ICU: Intensive Care Unit; IQR: Interquartile Range; LDH: Lactate Dehydrogenase; LOS: Length of Stay; $\mathrm{PaCO}_{2}$ : Partial pressure of carbon dioxide in arterial blood; $\mathrm{PaO}_{2}$ : Partial pressure of oxygen in arterial blood; PEEP: Positive end-expiratory pressure; PP: Prone Position; SAPS II: Simplified Acute Physiology Score II; SARS-COV-2: Severe Acute Respiratory Syndrome Coronavirus 2; SOFA: Sequential Organ Failure Assessment; SP: Supine Position; SD: Standard Deviation; VR: Ventilatory ratio.

\section{Supplementary Information}

The online version contains supplementary material available at https://doi. org/10.1186/s13054-021-03552-2.

Additional file 1. This additional file contains three additional tables and 1 additional figure.

\section{Acknowledgements}

We thank Marina Leonardelli (Ospedale Maggiore Policlinico) and Patrizia Minunno (Ospedale Maggiore Policlinico) for administrative support. We thank all the health care staff of the participating ICUs. These individuals were not compensated for their role in the study.

\section{PRONA-COVID Group:}

Angela Berselli ${ }^{6}$; Tiziana Bove ${ }^{17}$; Plinio Calligari ${ }^{18}$; Irene Coloretti ${ }^{10}$; Antonio Coluccello ${ }^{19}$; Elena Costantini ${ }^{14}$; Vito Fanelli ${ }^{20}$; Giuseppe Gagliardi ${ }^{21}$; Federico Longhini ${ }^{22}$; Federica Mariani ${ }^{9}$; Annalisa Mascarello ${ }^{1}$; Luca Menga ${ }^{11,12}$; Irene Ottaviani2 ${ }^{23}$; Daniela Pasero ${ }^{24,25}$; Matteo Pedeferri ${ }^{26}$; Angelo Pezzi ${ }^{27}$; Giuseppe Servillo ${ }^{28}$; Paolo Severgnini ${ }^{5}$; Savino Spadaro ${ }^{23}$; Vanessa Zambelli, ${ }^{1,15}$.

\section{Authors' contributions}

$T L, A G, M B$ and $G G$ conceived and designed the analysis; $T L, E C$ and $A G$ contributed in data management and performed statistical analyses; LC, GC, $F D C, E D R, M F, A F, C F, D L G, L M, V N, P P, A P, R R, F T, T T, F Z$ collected and analyzed data; TL, AG, MB, EC, GF, MG, MA, MR, AP, RF, GG contributed in data analysis, interpretation of the data and drafting the manuscript. All authors read and approved the final manuscript.

\section{Funding}

This study was funded by institutional funds of the Fondazione IRCCS Ca' Granda Ospedale Maggiore Policlinico, Milan, Italy. Ricerca Corrente 2020 and by project PB-0154 PROGETTO COVID-2020-12371675 "COVID19: EPIDEMIOLOGICAL, CLINICAL, GENETIC, AND SOCIAL DETERMINANTS OF INFECTION AND DISEASE PROGRESSION".

\section{Availability of data and materials}

The dataset used and/or analysed during the current study are available from the corresponding author on reasonable request.

\section{Declarations}

\section{Ethics approval and consent to participate}

This study was approved by the Ethical Committees of all participating centres (Promoting Centre's Ethical Committee: Comitato Etico Milano Area 2; protocol: 0008489; date of approval: March 20, 2020). The need for informed consent from individual patients was waived owing to the retrospective nature of the study.

\section{Consent for publication}

Not applicable.

\section{Competing interests}

The authors certify that they have no affiliations with, or involvement in any organization or entity with any financial or non-financial interest in the subject matter discussed in this manuscript.

\section{Author details}

${ }^{1}$ Department of Medicine and Surgery, University of Milan-Bicocca, Monza, Italy. ${ }^{2}$ Department of Anesthesia and Intensive Care Medicine, Niguarda Ca' Granda, Milan, Italy. ${ }^{3}$ Department of Anesthesia, Critical Care and Emergency, Fondazione IRCCS Ca' Granda Ospedale Maggiore Policlinico, Via Francesco Sforza 35, 20122 Milan, Italy. ${ }^{4}$ Department of Pathophysiology and Transplantation, University of Milan, Milan, Italy. ${ }^{5}$ Ospedale di Circolo e Fondazione Macchi, Università degli studi dell'Insubria, Varese, Italy. ${ }^{6}$ Department of Anesthesiology and Intensive Care, ASST Mantova-Ospedale Carlo Poma, Mantova, Italy. ${ }^{7}$ Department of Biomedical Sciences, Humanitas University, Pieve Emanuele, MI, Italy. ${ }^{8}$ Division of Anaesthesia, Analgesia and Intensive Care, Department of Medicine and Surgery, University of Perugia, Perugia, Italy. ${ }^{9}$ Department of Anesthesia and Intensive Care, A. Manzoni Hospital, ASST Lecco, Lecco, Italy. ${ }^{10}$ Department of Anesthesia and Intensive Care, University Hospital of Modena, Modena, Italy. ${ }^{11}$ Department of Anesthesiology, Intensive Care and Emergency Medicine, Fondazione Policlinico Universitario A. Gemelli IRCCS, Rome, Italy. ${ }^{12}$ Sacred Heart Catholic University, Rome, Italy.

${ }^{13}$ Department of Medical and Surgical Sciences, Intensive Care Unit, University of Foggia, Foggia, Italy. ${ }^{14}$ Department of Anaesthesia and Intensive Care, Humanitas Clinical and Research Center-IRCCS, Rozzano, MI, Italy. ${ }^{15}$ Department of Anesthesia and Intensive Care Medicine, San Gerardo Hospital ASST Monza, Monza, Italy. ${ }^{16}$ Anesthesia and Intensive Care Medicine, Policlinico di Sant'Orsola, Alma Mater Studiorum University of Bologna, Bologna, Italy. ${ }^{17}$ Department of Medicine, University of Udine, Udine, Italy. ${ }^{18}$ Plinio Calligari Ospedale Magalini Villafranca, Verona, Italy. ${ }^{19}$ Department of Anesthesiology and Intensive Care, ASST Cremona - Ospedale di Cremona, Cremona, Italy. ${ }^{20}$ Department of Surgical Science, Division of Anesthesia and Critical Care Medicine, University of Turin, AOU Città della Salute e della Scienza di Torino, Turin, Italy. ${ }^{21}$ UOC Anestesia e Rianimazione, AULSS 5 Polesana, Rovigo, Italy. ${ }^{22}$ Anesthesia and Intensive Care, Department of Medical and Surgical Sciences, "Magna Graecia" University, Catanzaro, Italy. ${ }^{23}$ Department Morphology, Surgery and Experimental Medicine, Section of Intensive Care, University of Ferrara, Ferrara, Italy. ${ }^{24}$ Anesthesia and Intensive Care Unit, AOU Sassari, Sassari, Italy. ${ }^{25}$ Department of Medical, Surgical and Sperimental Science, University of Sassari, Sassari, Italy. ${ }^{26}$ U.O.C. Anstesia e Rianimazione, Ospedale L. Mandic Merate, ASST Lecco, Merate, Italy. ${ }^{27}$ ASST Nord Milano, Ospedale "E. Bassini", San Giovanni, Italy. ${ }^{28}$ Dipartimento di Neuroscienze, scienze riproduttive e odontostomatologiche, Università degli studi di Napoli Federico II, Naples, Italy. 
Received: 2 February 2021 Accepted: 26 March 2021

Published online: 06 April 2021

\section{References}

1. Coronavirus COVID-19 global cases by the Center for Systems Science and Engineering (CSSE) at Johns Hopkins. [Internet]. https://gisanddata. maps.arcgis.com/apps/opsdashboard/index.html\#/bda7594740fd402 99423467b48e9ecf6.

2. Zhu N, Zhang D, Wang W, Li X, Yang B, Song J, et al. A novel coronavirus from patients with pneumonia in China, 2019. N Engl J Med. 2020;382(8):727-33.

3. Grasselli G, Zangrillo A, Zanella A, Antonelli M, Cabrini L, Castelli A, et al. Baseline characteristics and outcomes of 1591 patients infected with SARS-CoV-2 admitted to ICUs of the Lombardy Region, Italy. JAMA J Am Med Assoc. 2020;323(16):1574-81.

4. Grasselli G, Greco M, Zanella A, Albano G, Antonelli M, Bellani G, et al. Risk Factors Associated with Mortality among Patients with COVID-19 in Intensive Care Units in Lombardy, Italy. JAMA Intern Med. 2020;1-11.

5. Foti G, Giannini A, Bottino N, Castelli GP, Cecconi M, Grasselli G, et al. Management of critically ill patients with COVID-19: suggestions and instructions from the coordination of intensive care units of Lombardy. Minerva Anestesiol (Internet). 2020 Nov;86(11). https://www.minervamed ica.it/index2.php?show=R02Y2020N11A1234.

6. Grasselli G, Tonetti T, Protti A, Langer T, Girardis M, Bellani G, et al. Pathophysiology of COVID-19-associated acute respiratory distress syndrome: a multicentre prospective observational study. Lancet Respir Med. 2020;19:1201-8

7. Guérin C, Reignier J, Richard JC, Beuret P, Gacouin A, Boulain T, et al. Prone positioning in severe acute respiratory distress syndrome. N Engl J Med. 2013;368(23):2159-68.

8. Taccone P, Pesenti A, Latini R, Polli F, Vagginelli F, Mietto C, et al. Prone positioning in patients with moderate and severe acute respiratory distress syndrome: a randomized controlled trial. JAMA J Am Med Assoc 2009;302(18):1977-84.

9. Gattinoni L, Taccone P. Carlesso E, Marini JJ. Prone position in acute respiratory distress syndrome. Rationale, Indications, and Limits. Am J Respir Crit Care Med (Internet). 2013 Dec;188(11):1286-93. https://doi.org/10. 1164/rccm.201308-1532Cl.

10. Lamm WJE, Graham MM, Albert RK. Mechanism by which the prone position improves oxygenation in acute lung injury. Am J Respir Crit Care Med. 1994;150(1):184-93.

11. Cortney Henderson A, Sá RC, Theilmann RJ, Buxton RB, Kim Prisk G, Hopkins SR. The gravitational distribution of ventilation-perfusion ratio is more uniform in prone than supine posture in the normal human lung. J Appl Physiol. 2013;115(3):313-24.

12. Scaravilli V, Grasselli G, Castagna L, Zanella A, Isgrò S, Lucchini A, et al. Prone positioning improves oxygenation in spontaneously breathing nonintubated patients with hypoxemic acute respiratory failure: a retrospective study. J Crit Care (Internet). 2015;30(6):1390-4. https://doi.org/ 10.1016/j.jcrc.2015.07.008

13. Ng Z, Tay WC, Ho CHB. Awake prone positioning for non-intubated oxygen dependent COVID-19 pneumonia patients. Eur Respir J. 2020;2002571.

14. Munshi L, Fralick M, Fan E. Prone positioning in non-intubated patients with COVID-19: raising the bar. Lancet Respir Med (Internet). 2020;8(8):744-5. https://doi.org/10.1016/S2213-2600(20)30269-1.

15. Elharrar X, Trigui Y, Dols AM, Touchon F, Martinez S, Prud'Homme E, et al. Use of Prone Positioning in Nonintubated Patients with COVID19 and Hypoxemic Acute Respiratory Failure. JAMA J Am Med Assoc. 2020;323(22):2336-8.

16. Coppo A, Bellani G, Winterton D, Di Pierro M, Soria A, Faverio P, et al. Feasibility and physiological effects of prone positioning in non-intubated patients with acute respiratory failure due to COVID-19 (PRON-COVID): a prospective cohort study. Lancet Respir Med (Internet). 2020;8(8):765-74. https://doi.org/10.1016/S2213-2600(20)30268-X.
17. Weiss TT, Cerda F, Scott JB, Kaur R, Sungurlu S, Mirza SH, et al. Prone positioning for patients intubated for severe acute respiratory distress syndrome (ARDS) secondary to COVID-19: a retrospective observational cohort study. Br J Anaesth. 2020(January).

18. Mathews KS, Soh H, Shaefi S, Wang W, Bose S, Coca S, et al. Prone positioning and survival in mechanically ventilated patients with coronavirus disease 2019-related respiratory failure. Crit Care Med. 2021.

19. Ranieri VM, Rubenfeld GD, Thompson BT, Ferguson ND, Caldwell E, Fan E, et al. Acute respiratory distress syndrome: The Berlin definition. JAMA J Am Med Assoc. 2012;307(23):2526-33.

20. Charlson ME, Pompei P, Ales KL, Mackenzie CR. A new method of classifying prognostic comorbidity in longitudinal studies: Development and validation. J Chronic Dis (Internet). 1987 Jan;40(5):373-83. http://www. sciencedirect.com/science/article/pii/0021968187901718.

21. Vincent J-L, de Mendonca A, Cantraine F, Moreno R, Takala J, Suter PM, et al. Use of the SOFA score to assess the incidence of organ dysfunction/ failure in intensive care units. Crit Care Med (Internet). 1998;26(11):1793800. Available from: http://journals.lww.com/00003246-19981 1000-00016.

22. Knaus WA, Draper EA, Wagner DP, Zimmerman JE. APACHE II: a severity of disease classification system. Crit Care Med (Internet). 1985 Oct;13(10):818-29. http://www.ncbi.nlm.nih.gov/pubmed/3928249.

23. Le Gall JR, Lemeshow S, Saulnier F. A new simplified acute physiology score (SAPS II) based on a European/North American multicenter study. JAMA (Internet). 270(24):2957-63. http://www.ncbi.n/m.nih.gov/pub$\mathrm{med} / 8254858$.

24. Wexler HR, Lok P. A simple formula for adjusting arterial carbon dioxide tension. Can Anaesth Soc J (Internet). 1981;28(4):370-2. http://www.ncbi. nlm.nih.gov/pubmed/6790141.

25. Sinha P, Fauvel NJ, Singh S, Soni N. Ventilatory ratio: a simple bedside measure of ventilation. Br J Anaesth. 2009:102(5):692-7.

26. Gattinoni L, Vagginelli F, Carlesso E, Taccone P, Conte V, Chiumello D, et al. Decrease in Paco2 with prone position is predictive of improved outcome in acute respiratory distress syndrome. Crit Care Med. 2003:31(12):2727-33.

27. Albert RK, Keniston A, Baboi L, Ayzac L, Guérin C, Proseva Investigators. Prone position-induced improvement in gas exchange does not predict improved survival in the acute respiratory distress syndrome. Am J Respir Crit Care Med (Internet). 2014;189(4):494-6. http://www.ncbi.nlm.nih. gov/pubmed/24528322.

28. Duggal A, Rezoagli E, Pham T, McNicholas BA, Fan E, Bellani G, et al. Patterns of use of adjunctive therapies in patients with early moderate to severe ARDS: insights from the LUNG SAFE study. Chest (Internet). 2020;157(6):1497-505. https://doi.org/10.1016/j.chest.2020.01.041.

29. Bellani G, Laffey JG, Pham T, Fan E, Brochard L, Esteban A, et al. Epidemiology, patterns of care, and mortality for patients with acute respiratory distress syndrome in intensive care units in 50 countries. JAMA J Am Med Assoc. 2016;315(8):788-800

30. Chanques G, Constantin JM, Devlin JW, Ely EW, Fraser GL, Gélinas C, et al. Analgesia and sedation in patients with ARDS. Intensive Care Med (Internet). 2020. https://doi.org/10.1007/s00134-020-06307-9.

31. Guérin C, Albert RK, Beitler J, Gattinoni L, Jaber S, Marini JJ, et al. Prone position in ARDS patients: why, when, how and for whom. Intensive Care Med (Internet). 2020. https://doi.org/10.1007/s00134-020-06306-w.

32. Verelst $F$, Kuylen $E$, Beutels $P$. Indications for healthcare surge capacity in European countries facing an exponential increase in coronavirus disease (COVID-19) cases, March 2020. Eurosurveillance. 2020;25(13):1-4.

33. Pelosi P, Tubiolo D, Mascheroni D, Vicardi P, Crotti S, Valenza F, et al. Effects of the prone position on respiratory mechanics and gas exchange during acute lung injury. Am J Respir Crit Care Med. 1998;157(2):387-93.

34. Gattinoni L, Tognoni G, Pesenti A, Taccone P, Mascheroni D, Labarta V, et al. Effect of prone positioning on the survival of patients with acute respiratory failure. N Engl J Med (Internet). 2001;345(8):568-73. http:// www.ncbi.nlm.nih.gov/pubmed/11529210.

35. Lee HY, Cho J, Kwak N, Choi SM, Lee J, Park YS, et al. Improved oxygenation after prone positioning may be a predictor of survival in patients 
with acute respiratory distress syndrome*. Crit Care Med (Internet). 2020;48(12):1729-36. https://doi.org/10.1097/CCM.0000000000004611.

36. Lemasson S, Ayzac L, Girard R, Gaillard S, Pavaday K, Guérin C. Does gas exchange response to prone position predict mortality in hypoxemic acute respiratory failure? Intensive Care Med. 2006;32(12):1987-93.

37. Charron C, Repesse X, Bouferrache K, Bodson L, Castro S, Page B, et al. $\mathrm{PaCO} 2 a n d$ alveolar dead space are more relevant than $\mathrm{PaO} / \mathrm{FiO}$ ratio in monitoring the respiratory response to prone position in ARDS patients: A physiological study. Crit Care. 2011;15(4).
38. Protti A, Chiumello D, Cressoni M, Carlesso E, Mietto C, Berto V, et al. Relationship between gas exchange response to prone position and lung recruitability during acute respiratory failure. Intensive Care Med. 2009;35(6):1011-7.

\section{Publisher's Note}

Springer Nature remains neutral with regard to jurisdictional claims in published maps and institutional affiliations.
Ready to submit your research? Choose BMC and benefit from:

- fast, convenient online submission

- thorough peer review by experienced researchers in your field

- rapid publication on acceptance

- support for research data, including large and complex data types

- gold Open Access which fosters wider collaboration and increased citations

- maximum visibility for your research: over $100 \mathrm{M}$ website views per year

At BMC, research is always in progress.

Learn more biomedcentral.com/submissions 